\title{
Conducting a Street-Intercept Survey in an Authoritarian Regime: The Case of Myanmar
}

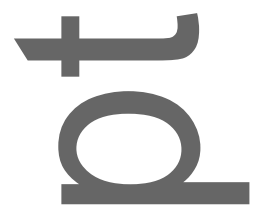

By Andy Buschmann

*Direct all correspondence to: Andy Buschmann, University of Michigan, Ann Arbor, Department of Political Science, 5700 Haven Hall, 505 South State Street, Ann Arbor, MI 48109-1045 (andybu@umich.edu). I thank Thint Myat for invaluable research assistance in Myanmar, Michael Biggs for comments on an earlier draft of this article, Nankyung Choi and the City University of Hong Kong for supporting the idea, and the organizers and participants of the Research-in-Progress Colloquiumat St Antony's College, Oxford, for their much-appreciated feedback on the bigger project.

\section{OMRC-Abstract}

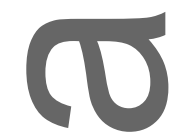

Object: In this research note, I share my experiences conducting a street-intercept survey in Yangon, Myanmar. The pre-study aimed to measure postmaterialism among Burmese using Roland Inglehart's four-item measure. The paper discusses the key features and advantages of the street-intercept survey method in difficult sociopolitical environments, the design and implementation of the study, as well as the results of the survey. Moreover, the ethics one ought to consider in authoritarian regimes are emphasized.

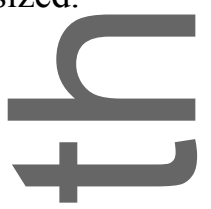

Methods: Original data was collected via a street-intercept survey in Yangon, Myanmar.

This is the and mascript accepted for publication and has undergone full peer review but has not been thr o th copyediting, typesetting, pagination and proofreading process, which may lead to differences betw this version and the Version of Record. Please cite this article as doi:

10.1111 ssqu. 12611.

This article is protected by copyright. All rights reserved. 
Results: The pre-study confirmed the feasibility and the advantages of the street-intercept survey method in Myanmar. At the same time, in Myanmar, difficulties in the translation of Inglehart's items raise questions regarding the applicability of this particular measure.

Conclusion This note will be useful for researchers intending to collect survey data in Myanmar and other authoritarian regimes.

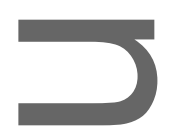

\section{Introduction}

In this research note, I share my experience of conducting a street survey that I undertook in March 2017 in Yangon, Myanmar. Equipped with a Burmese questionnaire, I asked randomly-selected pedestrians to rank four items in order of priority and, in addition, surveyed their basic sociodemographic data. The four items represent Roland Inglehart's four-item measure of postmaterialism (Inglehart, 1971). Inglehart defines the latter as a “...value orientation that emphasizes self-expression and quality of life over economic and physical security." (Inglehart, 2007, n.p.). The street survey was intended to serve as a pre-study for a project that aims to understand protest in post-2011 Myanmar, particularly youth-driven protest. When looking at contemporary Myanmar, it becomes evident that youth are at the vanguard of political activism. 'My project seeks to answer why this is the case. Social movement scholarship argues that, in order to overcome the fundamental problem of collective action (When do people take to the streets despite high personal cost and low personal gain?), individuals might need to have a particular set of values (Inglehart, 1990; Stern et al., 1999). Inglehart (1971) and Abramson and Inglehart (1987) propose postmaterialism as a value orientation that is conducive to political action. Indeed, previous 
scholarship has found postmaterialism to be positively associated with protest participation (e.g., Opp, 1990 for "legal" protests in the European context). Therefore, I wanted to probe whether or not postmaterialism can also be a useful concept to capture (potential) value-differences between youth and the broader society in Myanmar. "With this pre-study, I aimed to specifically answer two questions. Eirst, whether it was doable to conduct a survey study of this kind in contemporary Myanmar, and second, whether or not postmaterialism, operationalized in the common way, raises issues specific to Myanmar. Although I have decided to not further pursue this path for my project, the present note might prove useful in assisting researchers who want to employ the streetintercept survey method, or those who want to engage in similar work in Myanmar, or another (semi-) authoritarian country, in the future.

The remainder of the paper is structured as follows. Firstly, the street survey method, with its key features and its advantages over other survey methods, will be introduced. Secondly, the necessary preparatory work, e.g., the questionnaire design, will be discussed. Subsequently, the sampling strategy and data collection process will be examined, and finally the results presented. iii Furthermore, since the present research design has been greatly influenced by the specific setting of Myanmar as a former military dictatorship, the research ethics one ought to consider in such a context will be emphasized.

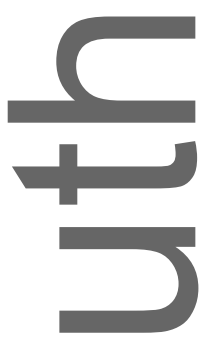

\section{The Street-Intercept Survey Method}

To the best of my knowledge, there is no reference text that introduces the intercept survey as a distinctive survey method. Therefore, I define the intercept survey here as a method that allows to 
collect in-person survey responses in a public or private area from people who are in, or passing by, the same area at the time the data collection takes place. By the ad hoc nature of intercept surveys, the interviews are usually brief, the survey questionnaires short and standardized, and the sample selection strategy non-probabilistic (i.e. "convenient").

Street-intercept surveys differ from intercept surveys in that they take place exclusively in public areas; they are therefore a subcategory of intercept surveys. ${ }^{\text {iv }}$ Scientific studies that have made use of street-intercept surveys make a good argument for the methodological features and benefits that render them useful in certain contexts (e.g., Deutsch \& Goulias, 2009; Grov, DeBusk, et al., 2007; Grov, Parsons, \& Bimbi, 2007; Miller, Wilder, Stillman, \& Becker, 1997; Rotheram-Borus et al., 2001). Street-intercept surveys, or as they are sometimes called 'street surveys,' are widely applied in public health and development studies, which hints at the fact that they have advantages in environments in which other survey methods fall short, especially in terms of compiling a 'representative' samplev . In the following, I will briefly discuss studies that demonstrate the usefulness of street-intercept surveys in contexts that are either characterized by: i. poverty, crime, and inequality, ii. the prevalence of social norms that impede survey research, or iii. dynamic change. With my pre-study, I add: iv. a repressive social- or political system, i.e. authoritarianism.

Miller et al. (1997) gathered health-related data from minority groups in impoverished suburbs with high crime rates in the US, and contend that "traditional population survey methods may produce inadequate sociodemographic profiles in [those] settings." (655) They argue that standard techniques draw an 'unrepresentative' picture of the population in areas that are characterized by poverty and crime. Telephone interviews (or CATI), for instance, disproportionately represent older people with higher incomes and employment, as well as from ethnic majorities, simply because landlines are not equally distributed amongst all sociodemographic properties but are more frequently found in higher socioeconomic strata. Thus, Miller et al. favor a street-intercept 
survey over other methods because of the better access to otherwise under-represented groups, leading possibly to an improved (substantive) 'representativeness' of the sample. Also, by comparing non-compliance rates from the street-intercept survey with those from other survey methods they applied, they find the highest compliance and response rates in the street-intercept survey.

Downing et al. (2014) chose the street-intercept survey method over standard interviews, telephone and self-administered surveys in Kenya, not only because many people in Nairobi do not have access to a telephone or a mail address, which makes probabilistic sampling strategies difficult to implement, but also because of the sensitivity of their research question (see also Russell, 2017). The researchers studied the "end-of-life care" preferences of Kenyans, and suggested that "...the sensitive nature of the topic meant that it would be important to establish a rapport between the person administering the survey and the respondent..." (2)

Conducting face-to-face interviews inhouse may sometimes be impossible due to social norms or concerns about anonymity. At the same time, human interaction and trust may still be indispensable for receiving truthful answers, which precludes non-interviewer-administered survey methods. In such situations, a street-intercept survey can be the only feasible option to collect survey data

Another field in d in which street-intercept surveys have been increasingly used is the survey of protesters during protests (e.g., Saunders, 2014; Walgrave \& Verhulst, 2011). Here, the method does not only allow interviewing activists who might otherwise be hesitant to participate in surveys, but the method is also commensurate with the possibility of fast-paced change in the survey setting. The high flexibility of street surveys in those environments is, in fact, also a feature of the "compactness" of the questionnaire, resulting from the necessary length limitation. It is revealing to this end that 
none of the street survey studies I have found during my desk research lasted more than 20 minutes, while the vast majority lasted only a couple of minutes.

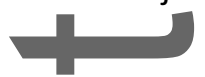

Researchers might not only seek to assuage non-compliance, non-responses and underrepresentation through the use of street-intercept surveys when they deal with sensitive survey questions or difficult environments. In some sociopolitical contexts, particularly in developing countries, there can be at least three more reasons why street-intercept surveys may be a preferred method option, especially compared to non-interviewer-administered surveys:

First, in self-administered surveys, a (more general) reason for a non-response can be the lack of familiarity with empirical research, which a face-to-face survey might mitigate because of the possibility of answering questions about the questionnaire. In fact, questions regarding the postmaterialism measure ("ranking in the order of priority") came up quite frequently during the survey in Yangon and could only be quickly answered because of the presence of the researcher. In other circumstances, those questions might have led to non-responses or random answers.

Second, standard face-to-face surveys can fall short in settings where family and household structures are unclear because they do not allow researchers to randomly select their interviewees. Even with the intention to randomly sample households, contracted enumerators might pass over to non-systematic sampling if household structures are unclear, which introduces biases to an extent unknown to the researcher (e.g., Bornstein, Jager, \& Putnick, 2013).

Third, besides these shortcomings, I also see a trust and security issue with standard face-toface surveys in an authoritarian context such as Myanmar. In standard face-to-face interviews, the targeted interviewees are commonly chosen by a (pseudo-) random selection of houses, and then by the last-birthday- or Kish-grid method. If the approached person agrees to participate, the interview is conducted inside the house. My experience in different cities in Myanmar was that many people 
who have lived most of their lives under military dictatorship, have, until today, remained cautious about being too exposed to the attention of others. One older woman, for example, told me that she believed her neighbors were (or still are) government informants. A foreign researcher, perhaps accompanied by a stranger, entering the home of a local resident can cause suspicion on the part of other residents, and might even cause trouble for the survey participants (e.g., Matelski, 2014). In fact, it is not only neighbors who can cause discomfort for the interviewees, but also the police or other parts of the state apparatus who might become watchful. It is at least difficult or even impossible to entirely preclude participants' risks without the involvement of the entire neighborhood, e.g. by informing the community collectively in advance about the purpose of the survey (which would introduce other biases and would be unfeasible in many cases anyway). Streetintercept surveys, if thoughtfully conducted, can significantly reduce these risks for participants. More details on this will follow later in the paper.

In this section, I have tried to define and characterize the usefulness of the street-intercept survey method and examined its strengths in terms of potential representativeness in difficult sociopolitical environments. In the following section, I will move back to my own study, discuss the design of the questionnaire, the selection of the district, as well as best practices I followed in preparation of the survey.

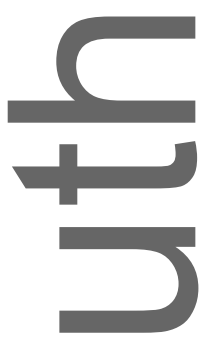

\section{Designing the Questionnaire}

Despite the critique that the postmaterialism-materialism concept and its measure developed by Roland Inglehart has received over the years (Clarke, Dutt, \& Rapkin, 1997; Davis \& Davenport, 1999; 
Inglehart \& Abramson, 1999), it has been widely used in surveys around the world. ${ }^{\text {vi }}$ Throughout the years, the same operationalization has been used in the measurement. ${ }^{\text {vii }}$ Postmaterialism, in fact, has continued to be an important concept in the social sciences, which makes it worth testing in Myanmar too. The 4-items measure is normally surveyed in the following standardized way

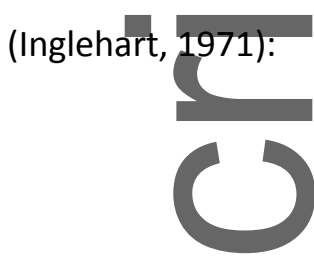

"For a nation, it is not always possible to obtain everything one might wish... several different goals are listed. If you had to choose among them, which one seems most desirable to you?

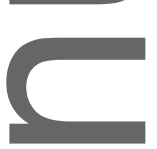

1. Maintaining order in the nation.

2. Giving the people more say in important political decisions.

3. Fighting rising prices.

\section{Protecting freedom of speech."}

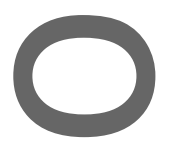

Because postmaterialism has, to the best of my knowledge, never been surveyed in Myanmar, I needed to translate the four items into Burmese myself. Brislin (1970) has proposed "backtranslation" as a best-practice to ensure that the meaning one wants to convey is what is actually understood in the respective context.

Back-translation works as follows. In the first step, a bilingual person who fully understands the purpose of the research and thus the meaning of the text, translates it into the local language. ${ }^{\text {vii }}$ 
In the second step, another bilingual native speaker who has not seen the English version before, translates the text back into English. The second step should be repeated several times with different people and all translations should be (almost) identical with the original.

While the last three items were relatively unproblematic in terms of back-translation, the first ("maintaining order in the nation") turned out to be difficult in Myanmar. The part "order in the nation" seems to have a very specific connotation there, which my Burmese friends linked with the chauvinist narrative of Burmese ethnic superiority, and with the "State Peace Law and Order Restoration Council", the name of the country's military junta from 1988 until 1997. After several trials, I ended up changing the first item to (literally translated): "The public follows the law."

While "law" in Myanmar is also understood as a mechanism to "order" social interaction, it is not the case that "law" represents solely the state's or the military's narrative, as seems to be the case with the term "order." Figure 1 shows the final translations.

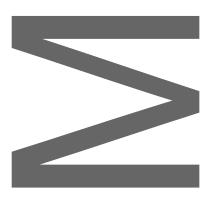

Figure 1 about here.

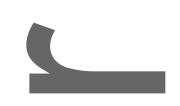

In addition, surveyed the standard sociodemographic variables of sex, age, education, and profession. Due to the political dimension of ethnicity and religion in Myanmar and the street survey format, I did not survey these data.

Since research on the validity of the postmaterialism measure has found that a different order of the items ean change the chances a certain item being prioritized over another (which would then not be due to any difference in "values" but only a bias; see Davis and Davenport, 1999), I decided to print the items on thick paper, cut it into strips and reshuffle them after each survey 
(see Figure 2). I numbered the four strips on the back and, during the survey, on an extra sheet, I noted down the order of the numbers according to the respondent's order of priority.

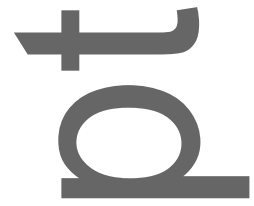

a

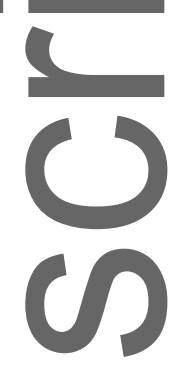

Figure 2 about here.

\section{Towards a 'Representative' Sampling Frame}

Although youth activism in Myanmar is not limited to Yangon, the city has always been a hotspot for political activism, and was therefore an obvious choice for the pre-study. However, Yangon has more than 7 million inhabitants, and consists of 33 townships. Drawing a sample from each of these townships to conduct a street-intercept survey would have exceeded the capacity of this study. It would have alsonot allowed me to draw a randomized sample of the whole population, which is demanded for a truly representative sample in the statistical sense. Hence, I compared the 33 townships in terms of size, citizens' status, education, housing, and employment by using the 2014 census data, and also "visually" by walking through neighborhoods in the different townships of Yangon and comparing the levels of "visual ordinariness." I finally selected Sanchaung in the Western Yangon district as a median candidate with regard to all the variables above, while also visually appearing to be a median township. At the time of the census in $2014,99,619$ people lived in Sanchaung, with a male population of $44.16 \%$. The mean household size was 4.2 persons, living in 87,228 "conventional" households (those that could clearly be assigned to a certain apartment and family). The literacy rate for the people aged 15 or above was $98.8 \%$, with $3.6 \%$ having not obtained any school qualification, $22.9 \%$ having left school after primary education, $30.6 \%$ having finished 
years 6-9 (middle school) and 43.3\% having accomplished years 10-11 (high school). The rest had a higher school qualification. The majority of the population were employees (31.6\%), $15 \%$ were selfemployed and $19.63 \%$ were unpaid household and family workers. $3 \%$ were unemployed (which excludes students, elderly, and disabled). Regarding the housing situation, $13.15 \%$ lived in wooden houses, bamboo houses, or under more precarious conditions (Union of Myanmar Ministry of Labour, 2017). Within Sanchaung, I selected streets close to a main road, where one would expect most sociodemographic diversity. Although certainly not a perfect representation of the whole of Yangon or eveh Myanmar, having chosen Sanchaung as a "median case" at least improved the odds of obtaining a more 'representative' sample.

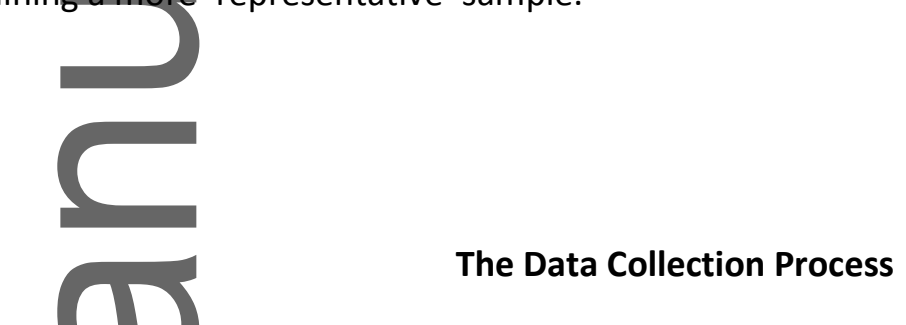

For a sample to be not systematically skewed, not only the location but also the day, time and the final sampling technique matters. Whitaker et al. (2012) for instance, interviewed an equal number of people during the working day and working hours and approached every third person they saw. In Nairobi, Downing et al. (2014) approached every $10^{\text {th }}$ person and alternated men and women. Due to time limitations, I selected (only) two different days and times. The first surveys were conducted on a Saturday afternoon (started at around 3pm). The second round was conducted on a Monday morning (at around 10am). During both time periods, the streets were busy with -- I expect -different groups of pedestrians. In order to select participants as randomly as possible, my Burmese research assistant and I walked down the main road and approached every $8^{\text {th }}$ (visually) adolescent or adult whowas walking towards us. I approached the selected person by saying in English: "Excuse me please, can I ask you a question?" Once I finished the sentence and no immediate reaction 
followed, my research assistant translated this into Burmese and added that I am a researcher from Germany. Then I showed the person the item strips and explained in English (followed by Burmese) that we would like to know what, in her or his opinion, the government should prioritize. After this question was answered with ordering the items, I showed the participant the answer sheet on which I had noted the order of the items, and pointed with my finger to the Burmese words for age, education, and profession. Doing this had three effects. First, the participant could see what I had noted down before, which made the whole process more transparent; second, the additional information (age, education, and profession) could be asked without the research assistant's translation; and, third, I could get a sense of whether or not the participant was literate. I added the sex after the participant had left.

Weskipped people who were in groups and did not continue with the survey if other people stopped (and became too interested) while a participant was considering the order of the items. This was not only to reduce a potential social desirability bias, but also to protect the respondents. Openly stating that freedom of speech should be a priority could still incur risks in a context such as Myanmar in 2017. Moreover, since I did not discriminate for certain characteristics, I had to also ask young females to answer the survey. Moral perceptions on a male-female interaction can be very conservative. In Myanmar, it is not common as a male person to talk to a young female when she is not accompanied by another person. Hence, for some women, the situation (us two young males) might have already been difficult to handle, which would have certainly been exacerbated by others closely abserving. Interestingly, in general, our endeavor did not draw much attention from the people around. On the one hand, this might indicate that foreigners have become much more common in Yangon, which positively affects the researcher bias. On the other hand, it might also be a result of the fact that the street survey method allowed us to be constantly moving. Because of the latter, I also tracked the way we walked with a mobile GPS app, which ought to increase the 
objectivity of the research. In total, we had only two non-responses. Once, a male person in his twenties just ignored us as if he had not recognized that I was talking to him. Another time, in the early evening, a young woman seemed to be scared of us.

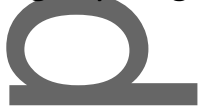

-

(

\section{The Results}

We originally targeted a sample size of about 100 . However, due to the limited amount of time we had at our disposal and the extensive sampling procedures outlined above (both rounds took approximately 2.5 hours each), we could only undertake 51 surveys. Table 1 summarizes the sociodemographic variables. Beside the gender distribution (the sample contains more than double the number of men although more women live in Sanchaung than men), all other variables match with the census profile described above. Figure 3 depicts the absolute distribution of postmaterialists, materialists, and mixed-(post-)materialists.

Figure 3 about here.

When respondents chose item 2 ("Giving the people more say in important political decisions") and 4 ("Protecting freedom of speech") in either order as one of the first two priorities, they are designated as being postmaterialists. If item 1 ("The public follows the law") and item 3 ("Fighting rising prices") were, in either order, the first two priorities, the respondents are designated as being materialists. If a materialist item follows a postmaterialist item, the person is designated as being a mixed-postmaterialist-materialist. For the reverse, she or he is designated as being a mixedmaterialist-postmaterialist. As Figure 3 shows, most participants in the sample are mixedmaterialists or materialists. Only half the number of materialists are postmaterialists. To put this into 
context, it might be worthwhile looking at the situation in Thailand, in which the World Values Survey also surveyed postmaterialism (with the 12-items scale). The distribution in Thailand is similarly skewed towards pure materialism with $9 \%$ and only $1.1 \%$ pure postmaterialism (World Values Survey Association, 2014). Unfortunately, only national-level data is available, meaning that only Thailand as a whole can be compared to Yangon.

According to the information we had collected on the respondents' occupation, I asked my Burmese research assistant to categorize each profession in terms of socioeconomic status into upper, middle, and lower class. Histograms for age and education can be found in the appendix.

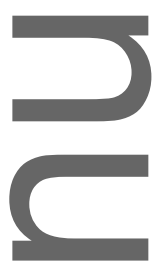

Table 1 about here.

In March 2017, I also conducted interviews with youth activists. At the end of the interviews, I asked my interviewees $(N=9)$ to rank the items according to their order of priority using the strips from the street survey. Differently from what I expected, the distribution was still skewed towards materialism (see Figure 4). One might argue that postmaterialism is simply not a necessary condition for protest participation, and that those activists are just protesting materialists. On the other hand, however, the similar distribution of (post-) materialism between the residents and the activists might also just indicate that the measure is biased (see Davis and Davenport's critique). For my project, I have decided that I will investigate value orientations by other means. Nevertheless, this does notnecessarily imply that the operationalization is invalid.

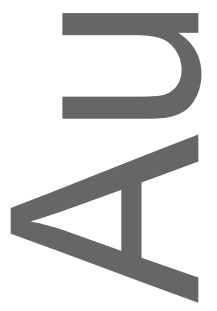


Figure 4 about here.

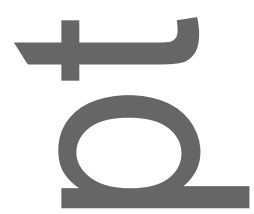

\section{Concluding Remarks}

As mentioned in the Introduction, I conducted the street-intercept survey to examine, first, whether it was doable to conduct such a survey in Myanmar and, second, if the operationalization of postmaterialism could be problematic in Myanmar. This paper has argued that, in some settings, a street survey has advantages over other methods, and I indeed confirmed this in Myanmar. Second, the translation of Inglehart's 4-items measure was difficult due to diverging understandings in the Myanmar context. Although a substitute item could be formulated, the results, particularly if compared to those of youth activists, seem to be too counter-intuitive to represent a true value orientation. Here, however, more research is needed. Besides the methodological introduction and the presentation of original data, this note identified Myanmar-specifics that researchers who plan to conduct similar research in Myanmar can hopefully build upon.
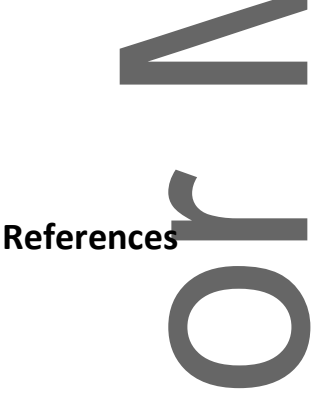

Abramson,P.R., \& Inglehart, R. F. (1987). Generational replacement and the future of postmaterialist values. The Journal of Politics, 49(1), 231-241.

Bornstein, M. H., Jager, J., \& Putnick, D. L. (2013). Sampling in Developmental Science: Situations, Shortcomings, Solutions, and Standards. Developmental review : DR, 33(4), 357-370. doi:10.1016/j.dr.2013.08.003 
Brislin, R. W. (1970). Back-Translation for Cross-Cultural Research. Journal of Cross-Cultural Psychology, 1(3), 185-216. doi:10.1177/135910457000100301

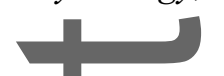

Buschmann, A. (2018). Introducing the Myanmar Protest Event Dataset: Motivation, Methodology and Research Prospects. Journal of Current Southeast Asian Affairs, 37(2), 125-142.

Clarke, H. D., Dutt, N., \& Rapkin, J. (1997). Conversations in context: The (mis) measurement of value change in advanced industrial societies. Political Behavior, 19(1), 19-39.

Davis, D. W., \& Davenport, C. (1999). Assessing the validity of the postmaterialism index. American political science review, 93(3), 649-664.

Deutsch, K., \& Goulias, K. (2009). Investigating the Impact of Sense of Place on Travel Behavior Using an Intercept Survey Methodology.

Downing, J., Gomes, B., Gikaara, N., Munene, G., Daveson, B. A., Powell, R. A., . . Harding, R. (2014). Public preferences and priorities for end-of-life care in Kenya: a population-based street survey. BMC Palliative Care, 13(1), 4. doi:10.1186/1472-684X-13-4

Grov, C., DeBusk, J. A., Bimbi, D. S., Golub, S. A., Nanin, J. E., \& Parsons, J. T. (2007).

Barebacking, the Internet, and harm reduction: an intercept survey with gay and bisexual men in Los Angeles and New York City. AIDS and Behavior, 11(4), 527-536.

Grov, C., Parsons, J. T., \& Bimbi, D. S. (2007). Sexual risk behavior and venues for meeting sex partners: an intercept survey of gay and bisexual men in LA and NYC. AIDS and Behavior, $11(6), 915-926$.

Inglehart, R. F. (1971). The Silent Revolution in Europe: Intergenerational Change in Post-Industrial Societies. The American Political Science Review, 65(4), 991-1017. doi:10.2307/1953494 
Inglehart, R. F. (1990). Values, Ideology and Cognitive Mobilization in New Social Movements:

Taylor \& Francis, Boca Raton.

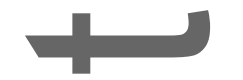

Inglehart, R. F. (2007). Postmaterialism. Retrieved from

https://www.britannica.com/topic/postmaterialism (last accessed on 2/24/2017)

Inglehart, R. F., \& Abramson, P. R. (1999). Measuring Postmaterialism. The American Political

Science Review, 93(3), 665-677.

Matelski, M.(2014). On sensitivity and secrecy: How foreign researchers and their local contacts in

Myanmar deal with risk under authoritarian rule. Journal of Burma Studies, 18(1), 59-82.

Miller, K. W., Wiłder, L. B., Stillman, F. A., \& Becker, D. M. (1997). The feasibility of a street-

intercept survey method in an African-American community. American Journal of Public

Health, 87(4), 655-658.

Opp, K.-D. (1990). Postmaterialism, Collective Action, and Political Protest. American Journal of Political Science, 34(1), 212-235. doi:10.2307/2111516

Rotheram-Borus, M. J., Mann, T., Newman, P. A., Grusky, O., Frerichs, R. R., Wight, R. G., \& Kuklinski, M. (2001). A street intercept survey to assess HIV-testing attitudes and behaviors. AIDS Education and Prevention, 13(3), 229-238.

Saunders, C. (2014). Anti-politics in action? Measurement dilemmas in the study of unconventional political participation. Political Research Quarterly, 67(3), 574-588.

Stern, P. C,Dietz, T., Abel, T., Guagnano, G. A., \& Kalof, L. (1999). A value-belief-norm theory of support for social movements: The case of environmentalism. Human ecology review, 81-97.

Union of Myanmar Ministry of Labour, I. a. P. (2017). Overview of the Results of the 2014 Population and Housing Census. Retrieved from 
Walgrave, S., \& Verhulst, J. (2011). Selection and Response Bias in Protest Surveys. Mobilization: An International Quarterly, 16(2), 203-222. doi:10.17813/maiq.16.2.j475m8627u4u8177

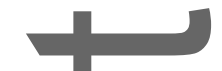

Whitaker, S., Baldwin, T., Tahir, M., Choudhry, O., Senior, A., \& Greenfield, S. (2012). Public knowledge of the symptoms of myocardial infarction: a street survey in Birmingham, England. Family Practice, 29(2), 168-173. doi:10.1093/fampra/cmr079

World Values Survey Association. (2014). World values survey wave 6 2010-2014 official aggregate v. 20150418: Vienna.

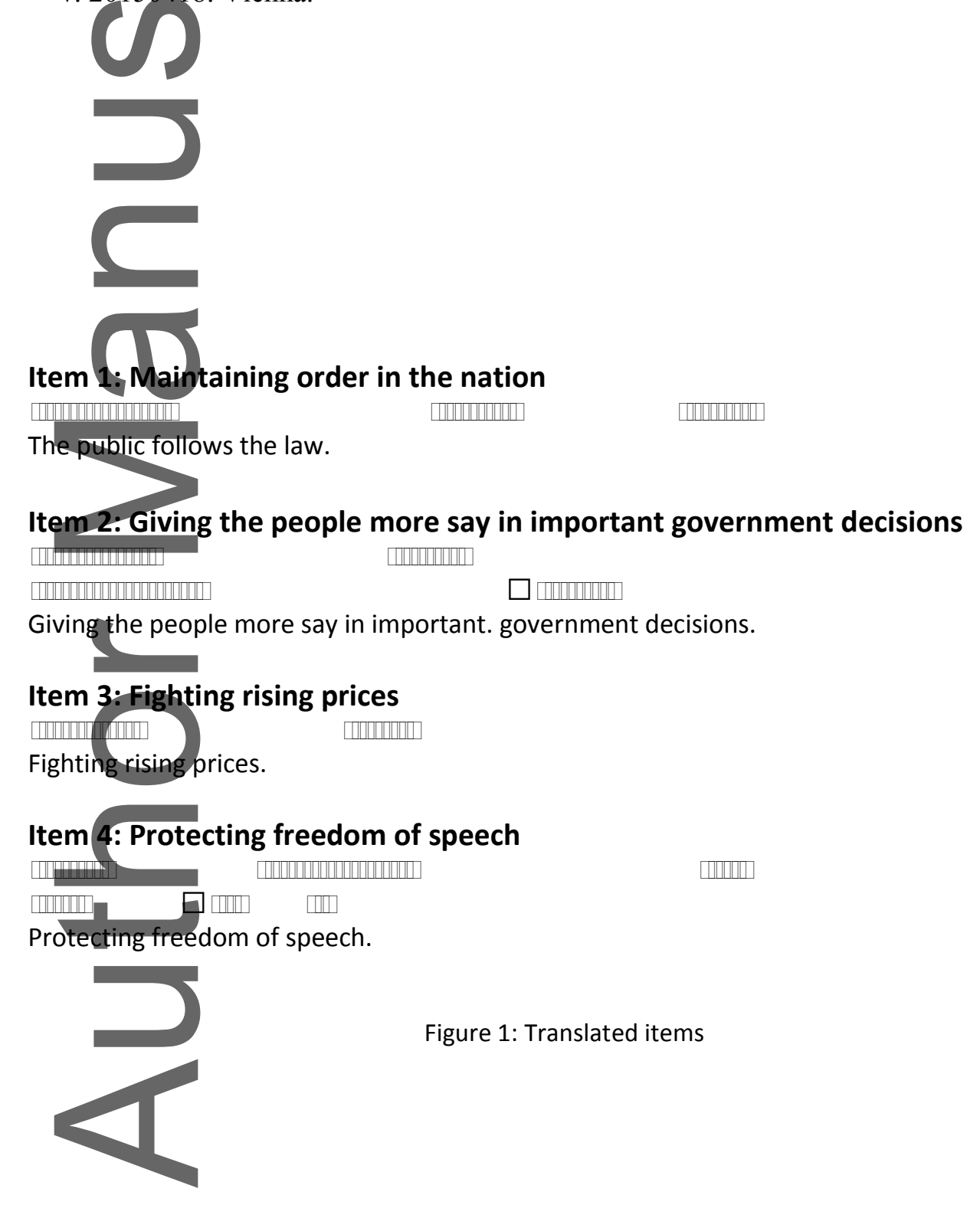




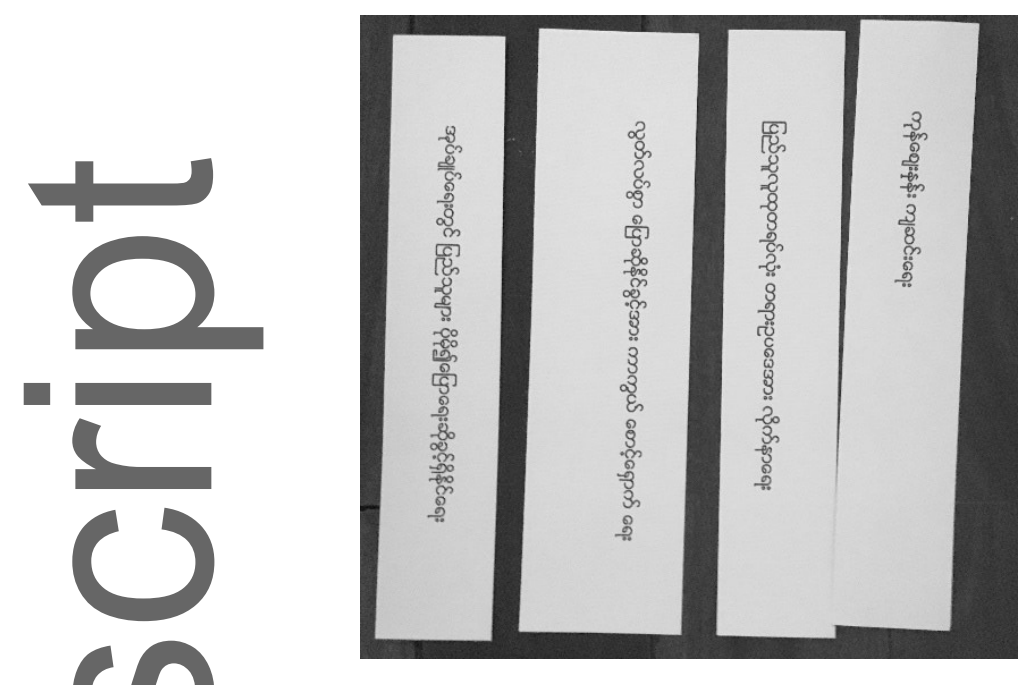

Figure 2: The four items on paper strips
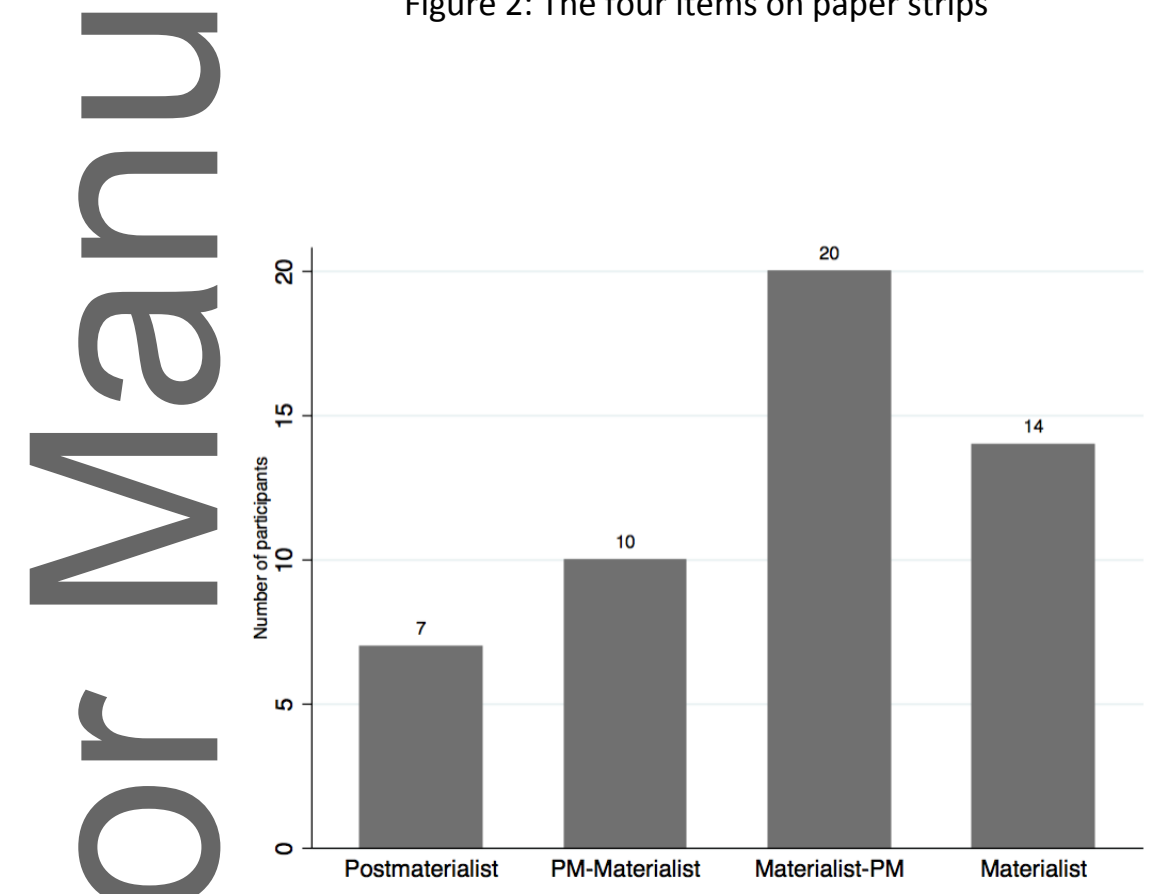

Figure 3: Distribution of value orientations

This article is protected by copyright. All rights reserved. 
Table 1: Summary of Sociodemographic Variables

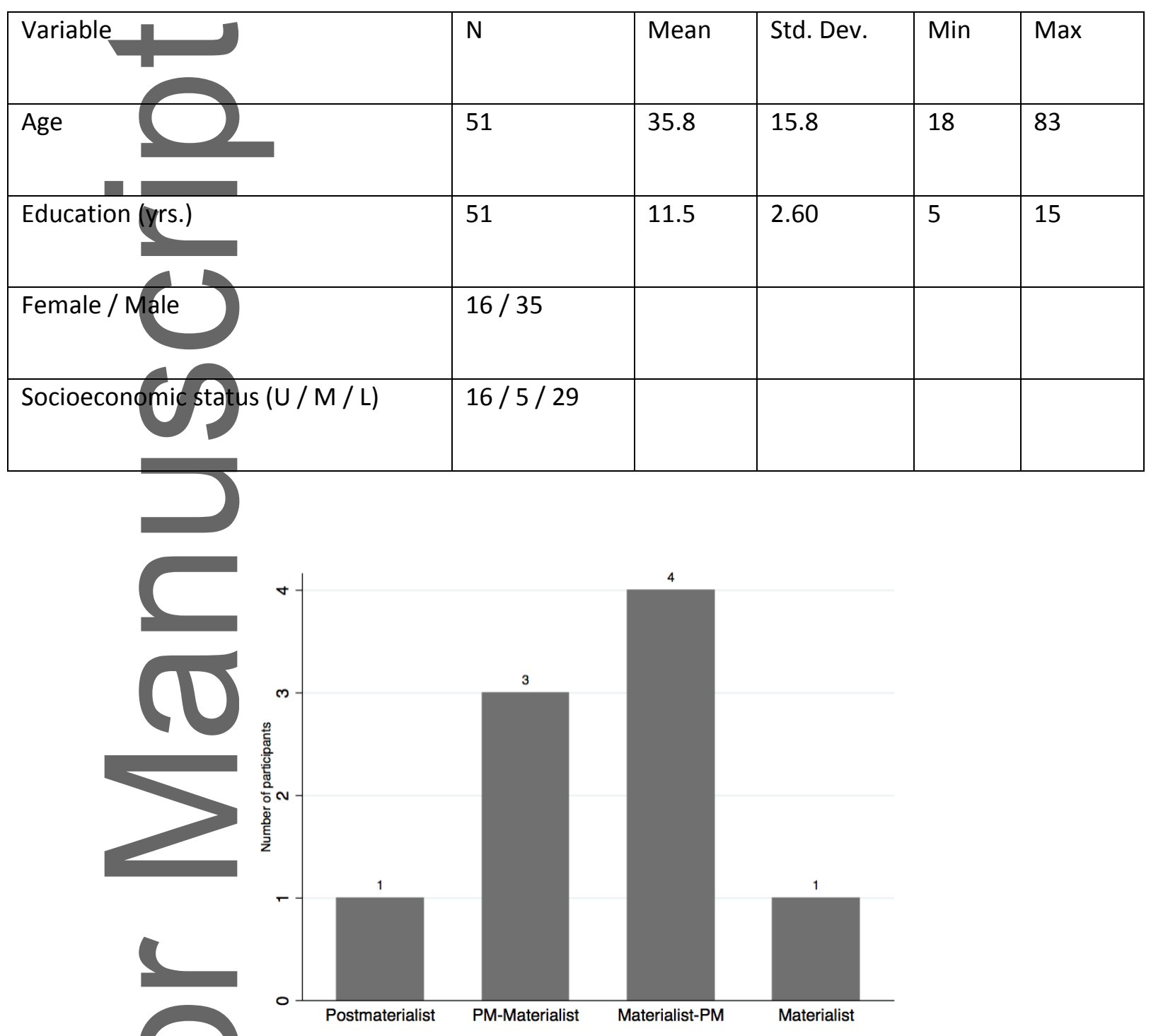

Figure 4: Distribution of value orientations among youth activists

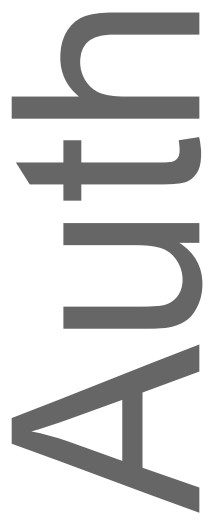

This article is protected by copyright. All rights reserved. 


\section{Appendix}

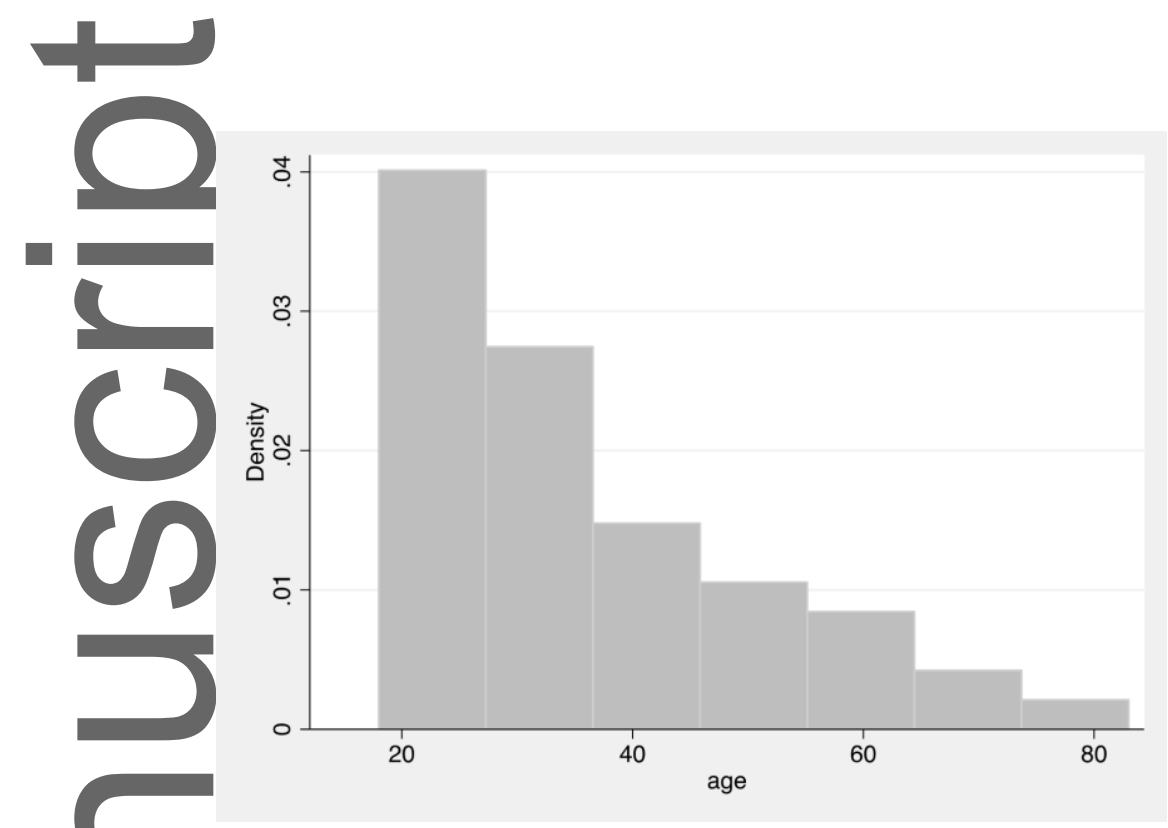

Figure A1: Sample distribution of age
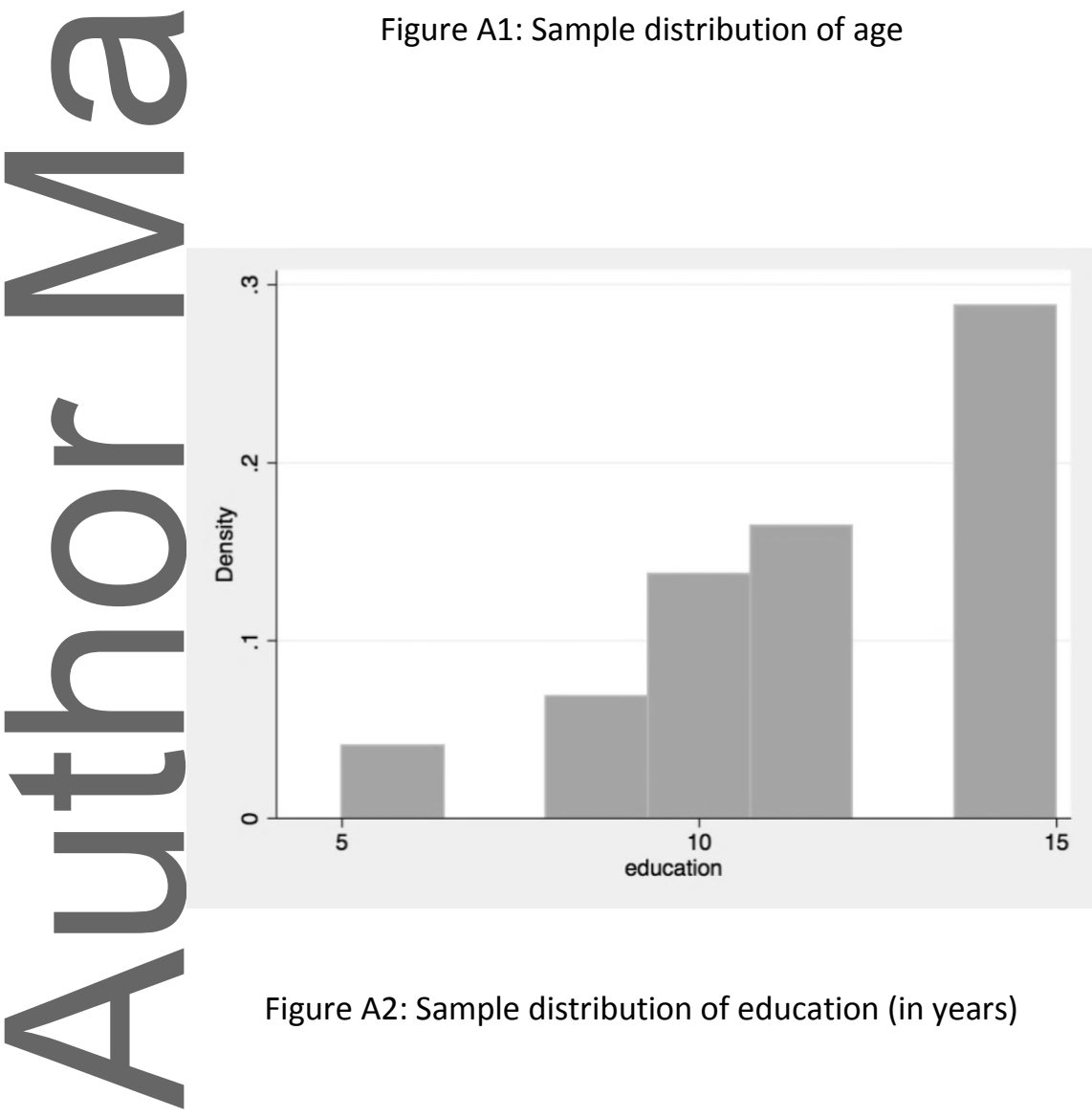

Figure A2: Sample distribution of education (in years)

This article is protected by copyright. All rights reserved. 
'According to data from the Myanmar Protest Even Dataset (Buschmann, 2018), from February 2011 to December 2014, roughly $15 \%$ of all protest events were staged by youth organizations. This figure is likely to have grown over the subsequent years and the issues that are aired at these protests are often closely related to democracy and political participation.

ii Postmaterialism has been explained by intergenerational value change that took place in post-WWII advanced industrialized countries in Europe (Inglehart, 1971). I did not intend to adopt the same explanation in Myanmar, but was rather interested in postmaterialism as a particular value orientation that may have other origins in non-Western contexts.

iii The survey data is available for download in the supplementary material.

iv 'Representative' should not be confused with 'random' in a statistical sense. A 'representative' but nonrandom sample includes units with certain (measurable) characteristics that the researcher believes are present in the target population.

${ }^{v}$ Although most of the points raised in the following apply to intercept surveys more generally, the discussion concentrates on the street-intercept survey method. Also, I do not discuss intercept surveys from marketing research her

${ }^{v i}$ The General Social Survey (GSS), the various Barometer studies, the World Value Survey (WVS), and even the German Socioeconomic Panel Survey (SOEP) as well as many other regional surveys have included the postmaterialism-materialism measure.

vii The WVS includes the 12 -items measure in their surveys.

viii For the translation task and the study at large, I needed to hire a Burmese speaker who was proficient in English, who was also not averse to accompanying me during the street survey, and had research experience. Fortunately, through my peers in the Myanmar-Institut e.V., a scholarly network for Burma studies in Europe, I could hire a person who met the requirements and was, as am I, in his mid-twenties.

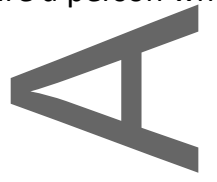

This article is protected by copyright. All rights reserved. 